$9-2020$

Developing role models in clinical settings: A qualitative study of medical students, residents and clinical teachers

Sonia ljaz Haider

Roger Christopher Gill

Qamar Riaz

Follow this and additional works at: https://ecommons.aku.edu/pakistan_fhs_mc_ded

Part of the Medical Education Commons, and the Surgery Commons 


\title{
Developing role models in clinical settings: A qualitative study of medical stu- dents, residents and clinical teachers
}

\author{
Sonia ljaz Haider1 ${ }^{1}$ Roger Christopher Gill2, Qamar Riaz³
}

\begin{abstract}
Objective: To explore how positive role modelling attributes can be developed in students, residents and clinical teachers. Methods: The qualitative study using focus group discussions was held at Aga Khan University, Karachi from March to May 2018, and comprised medical students, residents and clinical teachers. Overall 11 focus group discussions were conducted till data saturation was achieved. Content analysis was used to analyse the data which was transcribed verbatim.

Results: Of the 116 subjects, $60(51.7 \%)$ were medical students, 35(30.2\%) were residents and $21(18 \%)$ were clinical teachers. Of the 11 focus group discussions, 4(36.5\%) each were held with the students and the residents, while 3(27\%) were held with the teachers. Five major themes that emerged from the study included definition of role models, attributes of role models, role modelling as a learnt behaviour, challenges in developing role models, and recommendations for developing positive role models. A number of attributes of positive and negative role models were identified by the participants. All the participants including students, residents and teachers appreciated the importance of role modelling in developing professionalism among health professionals and medical students. Factors hindering development and demonstration of positive role modelling were also identified and possible solutions were suggested.

Conclusion: Clinical teachers needed to be made cognizant of their role as positive role models in developing professionally competent physicians. The medical institutions needed to develop and implement policies that would enhance positive role modelling by the teachers and facilitate learning of positive attributes at all levels.

Keywords: Role modelling, Health professionals, Focus group discussions.

(JPMA 70: 1498; 2020) DOI: https://doi.org/10.5455/JPMA.10336
\end{abstract}

\section{Introduction}

Role modelling is described as the process in which'faculty members demonstrate clinical skills, model and articulate expert thought processes and manifest positive professional characteristics. ${ }^{1}$ A key component of learning in medicine is by role modelling. Students learn by observing and role modelling professional values, behaviours and attitudes of their teachers in clinical settings. ${ }^{2}$

A number of studies have explored attributes of role models. In an early study Wright ${ }^{3}$ explored residents perceptions of role models and found demonstrating excellent clinical skills, teaching effectively and personality traits, such as compassion and empathy, as important characteristics of positive role models. Burgees et al ${ }^{4}$ also reported similar findings and concluded that role modelling played a critical role in influencing students' behaviour. Curry ${ }^{5}$ explored medical students' perceptions of role modelling in operation theatre (OT) and identified team interactions with patients (calm, communication and comforting), with one another (teamwork and respect) and with medical students (teaching) as pertinent attributes of

1,3Department of Educational Development, Aga Khan University, Karachi, Pakistan; 2Department of Surgery, Aga Khan University, Karachi, Pakistan. Correspondence: Qamar Riaz. e-mail: qamar_riaz66@yahoo.com positive role models. Other characteristics of positive role models have been reported as academically and clinically competent, caring attitude for patients, good interpersonal skills, providing constructive feedback, and maintaining respectful attitude.6-8

The impact of role modelling is significant in selecting clinical specialties among medical students. Yagazi ${ }^{9}$ reported that $38 \%$ of medical students and interns were influenced by their role models in choosing their clinical specialties. Ravindra ${ }^{10}$ found that junior doctors were twice as likely to express interest in pursuing a surgical career if they identified a positive surgical role model. According to Basco, ${ }^{11}$ most medical students identified a physician role model during their third year which, in turn, influences their specialty choice. Henderson 12 reported that positive role modelling by general internists was a significant factor in influencing medical students to choose primary care careers. In a recent study, Passi 13 reported that positive role modelling influenced development of professional behaviours, professional identity and career aspirations.

Majority of the existing studies have focussed on identifying characteristics of positive and negative role models, while others have examined the influence of role modelling on career choices of medical students. There is paucity of evidence exploring how positive role modelling 
attributes can be developed in students, residents and clinical teachers.

The current study was planned to explore how the positive attributes can be developed in medical students, residents and faculty, the perceived challenges in developing positive attributes, and identifying strategies for overcoming them.

\section{Subjects and Methods}

The qualitative study, with content analysis, was conducted at Aga Khan University (AKU), Karachi from March to May 2018. Approval was obtained from the ethics research committee of AKU, Karachi. The sample was raised using purposive sampling from among medical students, residents and clinical teachers. Medical students and residents in the final year of training in medical school at undergraduate and postgraduate levels were selected as they have better understanding of role modelling and its related issues. Clinical teachers in any discipline, having five years or more experience of teaching, and recognised as good teachers by students and residents evident through evaluations were identified as participants for the study. All the participants were invited through email. No relationship was established with the participants prior to commencement of the study. All the invited participants consented to participate in the study, and there were no drop-outs.

Data was collected through focus group discussions (FGDs) that were held between February and June, 2017. A total of 11 FGDs were conducted till the researchers felt that the data saturation had reached. Each FGD had the number of participants ranging from 7 to 16, in addition to the facilitator and the note-taker. All the FGDs were conducted in meeting rooms on the campus, each lasting about 50 minutes. Sessions were moderated by the researcher who had training in qualitative research and in conducting FGDs. The facilitator summarised the key findings after every session to gain agreement of the participants. The questions for the FGD were developed based on a review of the literature, ensuring introduction and discussion of further relevant topics. ${ }^{14}$

FGDs were audio-taped and transcribed verbatim manually. The transcripts were independently analysed manually for identification of codes by all the researchers. The coding categories were checked and refined by the research team. Two members of the research team were not clinical faculty members and were not involved in their teaching, assessment or evaluations. This eliminated any chance of introducing bias on the basis of preconceived ideas. The identified codes resulted in derivation of themes from the data. Consensus on the themes was reached after discussion among the researchers. The trigger questions served as orientation for coding, and subthemes were identified in an iterative process, which ensured that themes were comparable across groups. The trustworthiness of the data was ensured by memberchecking after each FGD, and independent analysis of the transcripts. ${ }^{15}$

\section{Results}

Of the 116 subjects, 60 (51.7\%) were medical students, 35 $(30.2 \%)$ were residents and $21(18 \%)$ were clinical teachers (Table-1). Of the 11 FGDs, 4 (36.5\%) each were held with the students and the residents, while $3(27 \%)$ were held with the teachers. Five distinct themes emerged as a result of the FGDS. These were: definition of role models; attributes of role models; role modelling as a learnt behaviour; challenges in developing positive role models; and recommendations for developing role models. No other minor themes emerged. Main aspects arising during FGDs along with participants' quotations were summed up (Table-2).

The first theme was defining role models. Role modelling was well perceived by a teacher as "It is a way you teach or shadow yourself to subordinates which could be your students, nursing staff or peers - the way you interact with patients and spend your life and day to day activities," (Teacher 11). Residents identified role models as "someone who inspires you at different levels, personal and professional and provides you with a trajectory you want to follow... You feel this is who you want to become" (Resident 7). Medical students indicated that "role modelling is a set of ideas you want to live by or measure up to" (student 5).

The second theme was attributes of role models. The essential attributes for role models that were commonly identified by clinical teachers, students and residents included ethical and moral practice, compassion, empathy, "puts himself in other's shoes" (resident), care, clinical competence, punctuality, professionalism, "Never comprises on integrity" (student 5), commitment to job, respectful interaction with patients and peers, honest

Table-1: Number of medical students, residents and faculty members by speciality.

\begin{tabular}{lccccccc}
\hline & \multicolumn{6}{c}{ Residents } & \multicolumn{3}{c}{ Clinical teachers } & \multicolumn{3}{c}{ Medical students** } & Total \\
& M & F & M & F & M & F & \\
\hline Surgery & 4 & 2 & 1 & 1 & & 8 \\
Medicine & 3 & 3 & 2 & 3 & & 11 \\
OBGYN** & - & 5 & - & 3 & & 8 \\
Psychiatry & 1 & 2 & - & 2 & & & 5 \\
Paediatrics & 3 & 5 & 1 & 4 & & & 13 \\
Radiology & 2 & - & 1 & 1 & & & 4 \\
Family medicine & 1 & 4 & - & 2 & & & 7 \\
Total & 14 & 21 & 4 & 17 & 28 & 32 & 116 \\
\hline
\end{tabular}


Table-2: Themes and sub-themes of developing role models in clinical settings

\begin{tabular}{|c|c|c|c|}
\hline Themes & Sub-themes & Supporting statements & Respondent \# \\
\hline \multirow[t]{5}{*}{ Defining role models } & \multirow[t]{2}{*}{ Inspires } & Qualities in some people you want to adopt..... & Student 21 \\
\hline & & role modelling is a set of ideas you want to live by or measure up to & Student 5 \\
\hline & Follow professionally & $\begin{array}{l}\text { Someone who inspires you at different levels, personal and professional and provides you with } \\
\text { a trajectory you want to follow...... You feel this is who you want to become }\end{array}$ & Resident 7 \\
\hline & Way of learning & It's like you observe and keep assimilating & Student14 \\
\hline & Portraying oneself & $\begin{array}{l}\text { It is a way you teach or shadow yourself to subordinates which could be your students, nursing staff } \\
\text { or peers - the way you interact with patients and spend your life and day to day activities, }\end{array}$ & Clinical Teacher 11 \\
\hline Attributes of role models & Competent & He excels as a clinician and teacher & Resident 5 \\
\hline \multirow[t]{12}{*}{ - positive role models } & Humane & Respects his colleagues and juniors & Clinical teacher13 \\
\hline & Interested in teaching & Active engagement with students, well prepared, to the point lectures & Student 10 \\
\hline & Learn from mistakes & Gives examples of how he learned through his errors & Resident 9 \\
\hline & Accept mistakes & Doesn't hesitate to admit fault & Clinical teacher 12 \\
\hline & Honest & Remains honest even if against him & Student 9 \\
\hline & Integrity & Never comprises on integrity & Resident 11 \\
\hline & Approachable & Gives adequate time, don't ignore & Student 5 \\
\hline & Professionalism & Follows rules, punctual, well disciplined, applies knowledge and experience & Clinical teacher 5 \\
\hline & Good communicator & Explains clearly & Student 22 \\
\hline & Knowledgeable & Upto date in his work & Clinical teacher 2 \\
\hline & Mentor & Continually improves students & Resident 2 \\
\hline & Caring & Always puts patient first & Clinical teacher 18 \\
\hline \multirow{6}{*}{$\begin{array}{l}\text { Attributes of role models } \\
\text { - negative role models }\end{array}$} & Always late & Doesn't come on time & Student 2 \\
\hline & Lack of professional attitude & Improper scrubbing / not wearing masks etc & Resident 3 \\
\hline & $\begin{array}{l}\text { Inadequate } \\
\text { communications skills }\end{array}$ & Some don't like to explain the patients or answer their queries & Student 4 \\
\hline & Don't invest time in students & Some faculty members are not interested in teaching as they think it hinders their clinical practice & Clinical teacher 9 \\
\hline & $\begin{array}{l}\text { Humiliating or mocking } \\
\text { others, make fun }\end{array}$ & "this is a silly question" & Student 19 \\
\hline & Temperamental & Treats different people differently & Resident 15 \\
\hline \multirow{7}{*}{$\begin{array}{l}\text { Role modelling as a } \\
\text { learnt behaviour }\end{array}$} & Conscious effort & We don't know if role modelling is happening; it should be more clear & Student 12 \\
\hline & Dependent on individual & If individual wants to be a role model, otherwise they wont & Clinical teacher3 \\
\hline & Inherent & Role models are born, they cannot be made & Clinical teacher 4 \\
\hline & \multirow[t]{2}{*}{ Developed behaviours } & Some characteristics can be developed others cannot & Resident 19 \\
\hline & & $\begin{array}{l}\text { "It depends on who their role model was; it is difficult to train teachers at their current level, } \\
\text { it is best to do so during training years" }\end{array}$ & Clinical Teacher 10 \\
\hline & \multirow[t]{2}{*}{ Learnt behaviour } & $\begin{array}{l}\text { Role Modelling comes from top to bottom - from consultant, fellow, resident etc. } \\
\text { if the consultant is not a good role model, his entire team will not be good role models too }\end{array}$ & Student 45 \\
\hline & & $\begin{array}{l}\text { It is not something you are born with; you are born with the affinity to do the right thing but } \\
\text { then you have to nurture everything which is good. }\end{array}$ & Clinical Teacher 1 \\
\hline \multirow{3}{*}{$\begin{array}{l}\text { Challenges in } \\
\text { developing role models }\end{array}$} & Over worked & There is too much work both for students and teachers & Clinical teacher11 \\
\hline & \multirow[t]{2}{*}{ Lack of time } & We run out of time always & Resident 23 \\
\hline & & $\begin{array}{l}\text { In clinical work you have to also fulfill financial target, If resident does something wrong, I may lose } \\
\text { my temperament as I am pressed for time and in that time I am not a positive role model }\end{array}$ & $\begin{array}{l}\text { Clinical Teacher } 3 \\
\text { Continued .......... }\end{array}$ \\
\hline
\end{tabular}

Vol. 70, No. 9, September 2020 
Table-2: continued from previous page.

\begin{tabular}{|c|c|c|c|}
\hline Themes & Sub-themes & Supporting statements & Respondent \# \\
\hline \multirow{9}{*}{$\begin{array}{l}\text { Challenges in } \\
\text { developing role models }\end{array}$} & \multirow[t]{2}{*}{ Changing mindset is difficult } & Seniors doesn't always listen & Resident 37 \\
\hline & & $\begin{array}{l}\text { Senior faculty doesn't always listen to you. Some people do listen while others do not. } \\
\text { Changing the mindset is difficult }\end{array}$ & Student 23 \\
\hline & \multirow{2}{*}{$\begin{array}{l}\text { Lack of interaction with } \\
\text { consultants }\end{array}$} & Consultants don't have time to teach & Student26 \\
\hline & & $\begin{array}{l}\text { Some consultants would ignore you and dislike your presence, and teaching you, } \\
\text { because they feel it hinders their speed in clinical practice }\end{array}$ & Resident 28 \\
\hline & Lack of policies & Systems should be there for practicing role modelling otherwise it won't work & Student35 \\
\hline & Lack of incentives & Good people should be rewarded & Student 32 \\
\hline & Diverse backgrounds & $\begin{array}{l}\text { Students come from all types of backgrounds with different values so not easy to make them } \\
\text { role models. And so does faculty }\end{array}$ & Resident 29 \\
\hline & Diverse experiences & $\begin{array}{l}\text { You can talk to someone about honesty and stuff without even realizing if that person had a } \\
\text { proper meal, is any other problem going on, actually make an effort to get involved and } \\
\text { build relations, it's very difficult to inspire them }\end{array}$ & Clinical Teacher 4 \\
\hline & Internal motivation & $\begin{array}{l}\text { It depends on the person, if they want to change and if they think there is room for improvement. } \\
\text { If they think there is no room for improvement, they won't accept and change for better }\end{array}$ & Resident 16 \\
\hline \multirow{15}{*}{$\begin{array}{l}\text { Recommendations for } \\
\text { developing positive } \\
\text { role models }\end{array}$} & \multirow[t]{3}{*}{ Using reinforcement } & $\begin{array}{l}\text { Identify negative influencing role models and take them out of the roster in fact replace them - } \\
\text { Make them accountable }\end{array}$ & Student 48 \\
\hline & & $\begin{array}{l}\text { Give incentives such as increase in salary or bonus, or acknowledgement on regular basis } \\
\text { like best teacher award etc }\end{array}$ & Clinical teacher 6 \\
\hline & & Develop sense of importance of teaching students & Student 41 \\
\hline & $\begin{array}{l}\text { Proper time and structure } \\
\text { for teaching }\end{array}$ & Students/resident should interact frequently with consultants & Student 27 \\
\hline & \multirow[t]{2}{*}{ Increase staff and resources } & We need more doctors, staff, clinics etc & Clinical teacher 7 \\
\hline & & $\begin{array}{l}\text { Increase number of doctors/residents, increase time with patients on wards. If given more time, } \\
\text { and workload reduced, they will be able to work effectively }\end{array}$ & Resident 18 \\
\hline & Role modelling in curriculum & $\begin{array}{l}\text { It should be part of our formal curriculum } \\
\text { There should be formal curriculum or syllabus about the domains and steps of role modelling for } \\
\text { each and every level. For example - a student can be a role model for a faculty- faculty can also learn } \\
\text { from students - So what attributes should be in students, residents and faculty should be clearly stated }\end{array}$ & $\begin{array}{l}\text { Student } 16 \\
\text { Teacher } 6\end{array}$ \\
\hline & Personal experience & maybe someone experienced personal experience/ trauma/ stress and thus needs counseling & Student 51 \\
\hline & $\begin{array}{l}\text { More awareness is needed } \\
\text { about role modelling }\end{array}$ & $\begin{array}{l}\text { Workshops and talks about role modelling } \\
\text { introduce role models from other parts of the world- trying to learn from people from other parts } \\
\text { of world can be inspiring }\end{array}$ & $\begin{array}{l}\text { Student } 52 \\
\text { Student } 55\end{array}$ \\
\hline & $\begin{array}{l}\text { Using reflection for } \\
\text { developing role modelling }\end{array}$ & We can ask students to reflect how they can become role models and that can help & Resident 15 \\
\hline & \multirow[t]{2}{*}{ Make it part of evaluation } & For both faculty and students it should be part of their appraisal & Clinical teacher 8 \\
\hline & & $\begin{array}{l}\text { "Marking system is usually on knowledge and clinical acumen; there should also be emphasis } \\
\text { on peer interaction or how are you with your peers or team }\end{array}$ & Student 32 \\
\hline & \multirow[t]{3}{*}{ Implementing policy } & Strict measures need to be taken to implement it & Clinical teacher 12 \\
\hline & & $\begin{array}{l}\text { policies are needed; those who do well should be rewarded, and those who don't, } \\
\text { system should take strict measures; no compromises }\end{array}$ & Clinical teacher 2 \\
\hline & & $\begin{array}{l}\text { Systems and policies are in place but people are not penalized for being ethical. There should be a } \\
\text { no tolerant policy for any breach and followed consistently no matter who does it for students, } \\
\text { residents, faculty, chair or director. Litigation and execution of the right principles in any society/ } \\
\text { culture is the first step }\end{array}$ & Clinical teacher 20 \\
\hline
\end{tabular}


communication, knowledge, good listening, ability to come down to level of students while teaching, approachable, not feared by students, and leadership. One of the teachers described positive role model as one who "follows rules, is punctual, well-disciplined, applies knowledge and experience" (Clinical Teacher 5).

Examples of negative behaviours included lack of professionalism, being rude to patients, students or staff or condescending behaviour "Looks down upon juniors and females" (resident). "Some don't like to explain the patients or answer their queries" (student 5); coming late, not listening or communicating effectively, not scrubbing or wearing masks during procedures and not involved in teaching "Some faculty members are not interested in teaching as they think it hinders their clinical practice" (Clinical Teacher 5).

The next theme was role modelling as a learnt behaviour. All the participants generally believed that role modelling can be developed and is a behaviour that can be learnt over a period of time. "Role Modelling comes from top to bottom - from consultant, fellow, residents etc. If the consultant is not a good role model, his entire team will not be good role model too," (Student 45).

According to teachers, "It is not something you are born with; you are born with the affinity to do the right thing but then you have to nurture everything which is good." (Clinical Teacher 1).

Participants indicated that conscious efforts were needed to bring about positive role modelling. Presently, even if positive role modelling is done, it remains unnoticed. Teachers indicated that although there is a top-down flow of role modelling, residents and students can also be minirole models.

Some residents and teachers were, however, sceptical in terms of developing role models. "Some characteristics can be developed, others cannot," (Resident 19). "It depends on who their role model was; it is difficult to train teachers at their current level, it is best to do so during training years" (Clinical Teacher 10). Teachers also emphasised that it depends on personal interest, "individuals can only be developed into role models if they want to be, otherwise not" (Clinical Teacher 3). They were of the opinion that there are some traits or qualities which are inherent, such as kindness, compassion and honesty, while there are other traits, like punctuality, ethics, teamwork, clinical competence and teaching skills, which can be developed, polished or rectified. Therefore complete transformation to positive role modelling may not be possible.

Challenges in developing role models: Positive role modelling is dependent on the individual. "It depends on the person, if they want to change and if they think there is room for improvement. If they think there is no room for improvement, they won't accept and change for the better." (Resident 16).

A number of challenges identified in developing role models were included, "senior faculty doesn't always listen to you. Some people do listen while others do not. Changing the mindset is difficult". (Student 23).

Workload and time constraints were identified as paramount factors hindering positive role modelling. "In clinical work you have to also fulfill financial target, If resident does something wrong, I may lose my temperament as I am pressed for time and in that time I am not a positive role model," (Teacher 3 ).

"Some consultants would ignore you and dislike your presence, and teaching you, because they feel it hinders their speed in clinical practice," (Resident 28).

Further it was stated that lack of policies related to role modelling is a major impediment in practising effective role modelling. Participants indicated that developing positive role models can be difficult. "You can talk to someone about honesty and stuff without even realising if that person had a proper meal, is any other problem going on, actually make an effort to get involved and build relations, it's very difficult to inspire them," (Teacher 4). Likewise, they emphasised that a large number of students come from diverse and difficult backgrounds, and, as positive role models, teachers need to be cognizant of this fact and their sensitivities.

And, finally, there were recommendations for developing role models. The participants emphasised the need for proper structure of teaching and interaction with residents and consultants, and time to practise role modelling. "Increase number of doctors/residents, increase time with patients on wards. If given more time, and workload reduced, they will be able to work effectively" (Resident 18).

Considering lack of time as a major issue, teachers proposed getting more time slots for doing clinical work and assigning a teaching day in which only new and prebooked patients were seen, so proper time can be allocated for student teaching. Students suggested identifying different ways of engaging students in learning despite busy schedules.

To promote positive role modelling, participants emphasised continuous assessment of role models from multiple perspectives. "Marking system is usually on knowledge and clinical acumen; there should also be 
emphasis on peer interaction or how you are with your peers or team" (Student 32).

They proposed having mentorship programmes and longitudinal themes in curriculum, for example, communication skills, work management, team leader, time management from initial years should be taught to both students and residents.

Participants indicated that role modelling should be in the curriculum. "There should be formal curriculum or syllabus about the domains and steps of role modelling for each and every level. For example, a student can be a role model for a faculty -- faculty can also learn from students. So what attributes should be in students, residents and faculty should be clearly stated" (Teacher 6).

Participants suggested implementation of policies, introducing accountability, and appreciation awards as a means to motivate teachers to develop them as role models. "Policies are needed; those who do well should be rewarded, and those who don't, the system should take strict measures; no compromises," (Teacher 2). Inspirational individuals in an institute should be invited on monthly or weekly basis to give lectures followed by discussion. They proposed having workshops for clinical teachers to facilitate them to understand and demonstrate role modelling. It was also proposed to "introduce role models from other parts of the world -- trying to learn from people from other parts of world can be inspiring," (Student 55). For self-development as role models, students suggested introducing reflection as a regular activity.

Regarding negative role models, the participants suggested exploring the reasons and providing counselling sessions, "maybe someone experienced personal experience/ trauma/ stress and thus needs counselling" (Student 51).

The participants emphasised the need for developing policies and systems for implementing role modelling "Systems and policies are in place, but people are not penalised for being unethical. There should be a notolerance policy for any breach and followed consistently no matter who does it for students, residents, faculty, chair or director. Litigation and execution of the right principles in any society/culture is the first step" (Teacher 20).

\section{Discussion}

The current study explored in depth the attributes of positive role models and the ways positive attributes can be developed in clinical teachers. Our results would be of interest to educationists and programme directors who prefer to develop students, residents and teachers as role models. One of the early studies ${ }^{3}$ used a 50-item questionnaire to examine perceptions of residents regarding role models. They reported personality, clinical, teaching and research traits as important attributes for physicians as role models. Findings of the present study are also similar with existing evidence which identified respect, opportunities to practice, safe environment and professionalism as important attributes for role models.

An interesting finding of the present study is that positive attributes can be learnt and developed. Hence, during medical school, students and residents can be encouraged and trained to develop these attributes. ${ }^{2}$ Students in the present study proposed reflection as a strategy for developing these attributes. Stark et al. ${ }^{16}$ demonstrated in their study that some aspects of professionalism, for example confidentiality, ethics, respect, care, prejudice and other related behaviours, like teamwork and communication, can be developed among medical students through guided reflective practice.

One of the challenges identified in promoting positive role modelling is bringing about any change in behaviour. Findings of the present study support that positive attributes can be developed which is contingent on the individual's inclination and motivation for continual improvement. Majority of the participants indicated that role modelling flows from top to bottom, and senior faculty is not usually amenable to change. However, measures were recommended in the study to encourage faculty to demonstrate positive role modelling. These included evaluation, incentivisation such as recognition, appreciation, monetary increment, and regular awareness workshops and trainings. Although these strategies may infuse enthusiasm and motivation, there is a possibility that some teachers still continue to resist it.

For the present study, one of the major challenges in encumbering positive role modelling is workload and time constraints. This was a concern raised by all the participants, but for teachers it was the only major issue obstructing positive role modelling. Lack of balance between time for clinical responsibilities and time for teaching has been reported by other studies. ${ }^{17,18}$ Increased number of students, few patients, opportunistic teaching at bedside and lack of resources are some of the reported challeges. ${ }^{19}$ In addition, clinicians are trained throughout medical school to achieve clinical competence without adequate preparation to teach. 20 Hence, it becomes cumbersome to manage time and workload effectively. To address some of the these issues, participants in the present study suggested increasing number of doctors for teaching, allotting less number of patients to doctors and increasing more time for teaching on wards rounds and in 
clinics. Cruess et al. also emphasised that institutional culture support can facilitate in promoting positive role modelling. ${ }^{21}$ However, to what extent the university and hospital is successful in bringing these changes is questionable because some of these policies are not so easily amenable to change.

From the perspective of learners, witnessing faculty demonstrating continuous display of positive attributes is expected to be embraced by the students. However, there may be instances when students are unable to do so. This is supported by existing evidence where students did not understand when role modelling happened and preferred that it should have been made explicit.22 Findings from the present study suggest that role modelling should be a longitudinal theme of the curriculum or syllabus in which steps of positive role modelling should be clearly delineated and attributes of positive role models defined. Teachers further proposed that a training programme should be implemented for all faculty, residents and students to get an in-depth understanding of how they can learn from each other. This is supported by existing evidence which emphasised that role models should delineate the complex intricacies of interacting with patients to help them understand and incorporate specific skills. ${ }^{23-25}$

Findings from the present study indicate that demonstrating positive role modelling is not always possible. Efforts should be made to understand the reasons for negative role modelling and facilitate them in behaving positively. There should be a 'no tolerance' policy for unethical or unprofessional behaviour for students, residents and faculty.

While an in-depth exploration was done related to development of clinical teachers as role models, conducting this study at a single centre was a limitation of the current study.

\section{Conclusion}

Role modelling is essential in inculcating essential desirable attributes in health professionals, including medical students, residents and faculty. However, there are factors that hinder both development and demonstration of positive role modelling. The faculty needs to be made cognizant of its role as positive role model in developing professionally competent physicians. Medical institutions need to develop and implement policies and strategies that would facilitate and enhance positive role modelling among professionals and learners at all levels.

\footnotetext{
Disclaimer: None.

Conflict of Interest: None. Source of Funding: None.
}

\section{References}

1. Irby DM. Clinical teaching and the clinical teacher. J Med Educ. 1986; 61:35-45.

2. Kenny NP, Mann KV, MacLeod H. Role modelling in physicians' professional formation: reconsidering an essential but untapped educational strategy. Acad Med. 2003; 78:1203-10.

3. Wright $\mathrm{S}$. Examining what residents look for in their role models. Acad Med. 1996; 71:290-2.

4. Burgess A, Goulston K, Oates K. Role modelling of clinical tutors: a focus group study among medical students. BMC Med Educ. 2015; 15:7.

5. Curry $\mathrm{SE}$, Cortland $\mathrm{Cl}$, Graham MJ. Role-modelling in the operating room: medical student observations of exemplary behaviour. Med Educ. 2011; 45:946-57.

6. Joubert PM, Kruger C, Bergh AM, Pickworth GE, Van Staden CW, Roos $\mathrm{JL}$, et al. Medical students on the value of role models for developing 'soft skills' - "That's the way you do it. Afr J Psychiatry. 2006; 9:28-32.

7. Kikukawa M, Nabeta H, Ono M, Emura S, Oda Y, Koizumi S, et al. The characteristics of a good clinical teacher as perceived by resident physicians in Japan: a qualitative study. BMC Med Educ. 2013; 13:100.

8. Jayasuriya-Illesinghe V, Nazeer I, Athauda L, Perera J. Role Models and Teachers: medical students perception of teaching-learning methods in clinical settings, a qualitative study from Sri Lanka. BMC Med Educ. 2016;16:52.

9. Yazigi A, Nassr M, Sleilaty G, Nemr E. The influence of clinical teachers as role models on the choice of specialty among Lebanese medical students. J Med Liban. 2006; 54:37.

10. Ravindra P, Fitzgerald JE. Defining surgical role models and their influence on career choice. World J Surg. 2011; 35:704-9.

11. Basco WT Jr, Reigart JR. When do medical students identify careerinfluencing physician role models? Acad Med. 2001; 76:380-2.

12. Henderson MC, Hunt DK, Williams JW Jr. General internists influence students to choose primary care careers: the power of role modelling. Am J Med. 1996; 101:648-53.

13. Passi V, Johnson N. The impact of positive doctor role modelling. Med Teach. 2016:1-7.

14. Kitzinger J. Focus groups. Qualitative research in health care. 2006; 3:21-31.

15. J.K. The methodology of focus groups: the importance of interaction between research participants. . Sociol Health Illn. 1994; 16:103-21.

16. Stark P, Roberts $C$, Newble D, Bax N. Discovering professionalism through guided reflection. Med Teach. 2006; 28:e25-31.

17. Fernandez Nievas IF, Thaver D. Work-Life Balance: A Different Scale for Doctors. Front Pediatr. 2015; 3:115.

18. Irby DM, Wilkerson L. Teaching when time is limited. BMJ. 2008; 336:384-7.

19. Spencer J. Learning and teaching in the clinical environment. BMJ. 2003; 326:591-4.

20. Ramani S. Twelve tips to improve bedside teaching. Med Teach. 2003; 25:112-5.

21. Cruess SR, Cruess RL, Steinert Y. Role modelling--making the most of a powerful teaching strategy. BMJ. 2008; 336:718-21.

22. Sternszus R, Macdonald ME, Steinert Y. Resident Role Modelling: "It Just Happens". Acad Med. 2016; 91:427-32.

23. Egnew TR, Wilson HJ. Role modelling the doctor-patient relationship in the clinical curriculum. Fam Med. 2011; 43:99-105.

24. Roberts NK, Dorsey JK, Wold B. Unprofessional behavior by specialty: a qualitative analysis of six years of student perceptions of medical school faculty. Med Teach 2014; 36:621-5.

25. Rougas S, Gentilesco B, Green E, Flores L. Twelve tips for addressing medical student and resident physician lapses in professionalism. Med Teach. 2015; 37:901-7. 